\title{
Analysis on the Reasons for Difficult Employment of College Students and Its Countermeasures
}

\author{
Jun Wang \\ School of Marxism \\ Wuhan University of Science and Technology \\ Wuhan, China 430065
}

\author{
$\mathrm{Xu}$ Liu \\ School of Marxism \\ Wuhan University of Science and Technology \\ Wuhan, China 430065
}

\begin{abstract}
The problem of college students' employment is becoming more and more prominent, which has become a hot issue of social concern. This paper briefly analyzes the subjective and objective reasons for the employment difficulties of college students, and puts forward corresponding solutions from the perspectives of national, university and students.
\end{abstract}

Keywords-college students' employment; reasons; countermeasures

\section{INTRODUCTION}

The employment problem is the biggest livelihood issue in China, especially the employment of college students. In recent years, the high number of graduates in colleges and universities across the country, according to data released by the ministry of human resources and social security, in 2017, the number of university graduates nationwide reached a record high of 7.95 million. Coupled with graduates who did not achieve employment in the past, the employment situation of university graduates is not optimistic. It is of great significance to improve the current employment situation and relieve the employment pressure by further study the employment problem of college students and explore countermeasures.

\section{ANALYSIS OF THE REASONS FOR THE DIFFICULT EMPLOYMENT OF COLLEGE STUDENTS}

\section{A. Objective Reasons}

1) The overall employment situation of the society is grim: The root of the increase in employment lies in the development of the economy, and the economic growth has an important pull on the employment. At present, China's economy has entered a new normal. The growth rate of the economy has shifted from the past high speed to the medium and high speed, and the slowdown of economic growth has reduced employment opportunities to some extent. The number of new labor force increasing every year in cities across the country is increasing. The number of jobs that the society can provide is relatively limited, and the number of college graduates is still stay in a high position without going down. The structural contradiction between supply and demand objectively causes employment difficulties for college students.

2) The national employment and entrepreneurship policy is imperfect: In order to promote the multi-channel employment and entrepreneurship of college graduates, the state has adopted a series of policies, such as tuition compensation, higher wages, tax credits, social security subsidies, entrepreneurial guarantee loans, and so on. Government purchase of grassroots public administration and social service development jobs and overall implementation of grassroots service projects such as the "Three Supports and One Assistance", so as to encourage graduates to go to urban and rural grass-roots areas, Midwest areas, hard and remote areas, and small and medium-sized enterprises. However, many employment and entrepreneurship policies lack the supporting implementation rules in the concrete implementation process, and the policy lacks operability so that the policy effect can not meet the expectations. For example, the state encourages graduates to work in small and medium-sized enterprises and non-public enterprises. The policy stipulates that small and medium-sized enterprises should be eligible for college graduates, and they can enjoy relevant subsidies and tax deductions and other policies. But in practice, small and medium-sized enterprises are relatively less employed by college graduates, and they prefer to hire people with working experience. In implementing the relevant national policies on entrepreneurship and employment, many universities and colleges have focused on issuing policy documents and publicizing policies in writing, and lack of specific and feasible guidance and explanation on employment policies, resulting in many university graduates lack of understanding of the country's relevant employment and entrepreneurship policy, cannot make full use of national policies to achieve the employment and entrepreneurship.

3) Disconnection between the talent training structure and the job market: Under the background of market economy, the employment of college students has been marketized. However, the professional setting and training mode of some colleges and universities have not kept up with the development of marketization. This highlights the fact that the professional setting does not take into account the actual 
needs of the society, and the professional setting is too narrow, resulting in a single ability of students. At the same time, the convergence of some professional settings, resulting in the number of similar talent training surplus. In education mode, it is still in the old mode of cultivation, focusing on the teaching of theoretical knowledge and neglecting the cultivation of students' practical ability, which leads to the lack of practice and innovation ability of students.

4) Insufficient effective employment guidance in colleges and universities: In order to realize the healthy and sustainable development of higher education, colleges and universities should pay attention to the effective employment guidance of college students, consistently adhering to satisfying the country' s social needs throughout the entire process of talents training and achieving a benign interaction between talent cultivation and university graduate employment while strengthening the training of talents. Effective employment guidance in colleges and universities can help students to correctly position themselves according to their majors and current social development situations so that they can clearly identify employment directions and establish a correct view of employment so as to achieve smooth employment. However, in practice, many universities only pay attention to the training of education, while the effective employment guidance is relatively inadequate. On the one hand, the employment guidance curriculum is not reasonable. The course content of employment guidance is relatively old and theoretical, which is divorced from the actual needs of society. Many colleges and universities tend to focus only on the instillation of employment theory knowledge, lack of specific and targeted employment practice guidance. The time setting of employment guidance course is shorter, and it is usually only one semester, which can't be used for four years, so that students cannot systematically study and master effective employment knowledge. On the other hand, the construction of employment guidance team is relatively backward. It is mainly manifested in the number of full-time teachers and the lack of professionalism. Some of the career guidance teachers are also part of student management. It is difficult to devote all their energies to employment guidance.

\section{B. Subjective Reasons}

1) College students are not qualified for professional skills: College study life is not as tense as high school, and there is no pressure for further studies in high schools, so many college students have relaxed their minds and become less demanding than in high school. The university is dominated by students' self-management. Due to the poor self-control ability of college students, it is not uncommon for the students to play mobile phones and sleep in the classroom. In addition, many college students spend most of their time and energy participating in club activities and fall in love without sufficient time and energy, so that there is not enough time and energy in the study of professional knowledge, which leads to the deficiency of master of professional knowledge. In the process of job hunting, college students are eliminated by employers due to their lack of professional knowledge or unskilled operation skills. Therefore, the lack of College Students' own skills is an important reason for their difficult employment.

2) Deviations in employment concept among university students: First of all, university graduates have a high expectation of employment during the employment process. They focus on selecting first-tier cities, party and government agencies, state-owned enterprises, and foreign-owned enterprises such as Bei-Shang-Guang-Shen. They think that only in this way can they reflect their values in life, and less consider whether their expectations for job selection are in line with The actual situation, whether the selected occupation meets the needs of the current society, whether it can give full play to their professional knowledge and advantages. They always hope to get good treatment and good positions immediately, but they are not willing to undergo training and gain experience at the grassroots level. Secondly, the employment of college graduates motivation show utilitarian tendency, the employment of college graduates motivation show utilitarian tendency, more and more emphasis on personal interests and individual development, to pay more attention to the immediate and short-term interests unconditionally. They are too self-centered, less take into account the needs of the state and society, lack of professionalism and dedication, and show a narrow sense of the criteria for the realization of self worth. Third, lack of competition awareness, excessive pursuit of stability. As a result of the long-term stable campus life and the psychological dependence on the family, so that some college graduates can not bear the pressure of employment, coupled with the lack of social practice experience, in the face of social pressure and employment problems, the psychological adjustment capacity is weak, competition awareness is insufficient. Many graduates of the employment of the first choice is a stable job, tend to good treatment of party and State organs, SOEs and institutions, but these units each year the number of recruitment staff is limited, and all aspects of high demand, can not meet the employment needs of too many university graduates. When some college graduates have suffered a setback in the process of job hunting, they have no strong will to face the challenge and dare not face the reality. In the face of the severe employment situation, some people often escape from finding jobs and choose "slow employment". University graduates in the choice of careers to seek stability and fear change, pursue comfortable and lowrisk jobs, lack of competition awareness, unwilling to try to have a risk and challenging career, pioneering innovation spirit is inadequate, self-entrepreneurship awareness is inadequate. The deviation of employment concept is one of the important reasons for college students' employment difficulties. 


\section{COUNTERMEASURES TO SOLVE THE EMPLOYMENT DifFICULTIES OF COLLEGE STUDENTS}

\section{A. National Aspects}

1) The country should create a good employment environment: We must adhere to the market-oriented employment mechanism, respect the position of workers and enterprises as the main source of market supply and demand, eliminate factors that affect the Equal employment system, such as differences between urban and rural areas, industries, identities and gender, and form a market system that is conducive to the free flow and equal exchange of labor factors, so as to improve the efficiency and fairness of the allocation of human resources. The quality of the employment environment will directly affect the smooth employment of university graduates. Therefore, the relevant departments of the state should take active measures to create a favorable employment environment and help the graduates to smooth employment. On the one hand, the state must maintain steady and rapid economic development. Only development can provide more jobs. We should accelerate the structural reform of supply and upgrade the industrial structure, increase the proportion of the tertiary industry and actively support and develop small and medium-sized enterprises, so as to provide more employment opportunities for college graduates. On the other hand, the state should constantly improve the policy of employment support for college students. First, we will formulate and improve relevant laws and regulations to ensure the legitimate rights and interests of college students' employment and realize the fairness and justice of the job market for college graduates. Second, improve the operability and motivation of employment support policies. We should formulate policies that are more operational and stimulating, and to further create conditions for university graduates to find employment at the grass-roots level in urban and rural areas, in the central and western regions, in difficult remote areas and in small and medium-sized enterprises. We need set up special departments to ensure the implementation of policies on social security subsidies, training subsidies, tax exemptions, the placement of graduates and the administration of personnel records, and support more graduates to build up their achievements at the grass-roots level and increase the enthusiasm of university graduates to find employment at the grass-roots level.

2) Improve the system of supporting entrepreneurship policy and encourage college students to start their own business: Innovation is the soul of social progress, and entrepreneurship is an important way to promote economic and social development and improve the people's livelihood. We need to further streamline administration and delegate power, increase financial and fiscal support, improve the system of supporting entrepreneurship, and lead businesses with innovation and create jobs through entrepreneurship. The Opinions on Strengthening and Implementing the Strategy of Innovation-Driven Development to Promote the Further
Development of Popular Entrepreneurship is issued in July of 2017 to encourage the college students' independent startup. On the one hand, we should enhance the operability of entrepreneurship support policies and reduce the conditions of the policy of entrepreneurship support. The establishment of a special college entrepreneurship service center and other organizations to conduct policy guidance for university entrepreneurship activities. Refining the content of business service and enhancing the pertinence of service. Shorten the application process for enterprise subsidy, widen the coverage of preferential support policies and improve the efficiency of service $。$ On the other hand, the policy of tax relief and loan financing should be improved. We will improve the policy of tax relief for college students and reduce the burden of starting a business. Widen the financing channels of loan, simplify the financing procedures of the venture loan and raise the limit of loan financing limit, so as to provide convenience for college students to start their business.

\section{B. Colleges and Universities.}

1) Reform the talent training mechanism and promote the quality education: At present, the difficulty of college students' employment reflects the unscientific problem of talent cultivation mechanism and method, and the talent cultivation in colleges and universities has a certain degree of decoupling from social needs. In order to cultivate high-level talents, colleges and universities should timely adjust discipline structure, personnel training structure and training mode according to industrial structure adjustment, social demand for talents and school orientation and conditions, so as to connect talents training with social needs. We should adjust our majors and disciplines according to the types of talents needed in the job market. In the enrollment scale, we should take full account of the market capacity and the conditions of running a school, and reasonably recruit students to ensure the quality of teaching and the future development of students. To reform the training mode, while paying attention to the theoretical training, we should strengthen the training of students 'practical ability, improve the comprehensive quality of students in all respects and cultivate more students with innovative spirit and practical ability.

2) Effective employment guidance: Effective employment guidance in colleges and universities can help graduates achieve better employment. Firstly, while strengthening the training of talents, colleges and universities should attach great importance to the employment guidance of college students. We should continue to strengthen the construction of the teaching staff of employment guidance courses and introduce specialized personnel. Discipline construction and enhance the employment guidance course, want to combine the current economic development of new forms and new normal, the dynamic of disciplines and industry development in time into the classroom teaching, improve the classroom teaching of engagement and attractive. We should conduct 
individualized counseling and counseling to help college graduates establish their career goals rationally, and in time to relieve them of anxiety, dependence and other psychological problems in the process of seeking employment, so as to enhance their ability to cope with competition and frustration. Actively organize extracurricular activities such as career planning competitions and career experience projects, give full play to the driving role of employment practice activities, and further improve the coverage and effectiveness of employment guidance. Secondly, we should give full play to the main channel and basic role of the campus employment market, dig deep into jobs, and actively organize various forms of campus recruitment activities, so as to ensure that the number of recruitment activities and positions is further increased, and the information quality is further improved. Finally, we will further strengthen the publicity of education and employment policy, and organize and guide graduates to carry out practical practices in urban and rural areas, so as to promote their knowledge of national conditions, society, ideas and capabilities. We need to help graduates to adjust their employment expectations, plan their careers, and actively pursue employment and entrepreneurship through the experience of excellent alumni, experts and scholars, and typical entrepreneurs.

\section{Personal Aspects of Students}

1) Establish a correct view of employment: Facing the current severe employment situation, college students should establish a correct view of employment, take active action and face the fierce competition. First of all, there must be a clear self-positioning. College students should combine the current employment situation, have a complete grasp of their major, work ability, hobby and other specialty, and fully know themselves, objectively evaluate themselves, according to their actual situation to find suitable jobs. Second, there must be full psychological preparation. In the process of choosing a career, college students will inevitably suffer setbacks. Therefore, the college students must learn to control their own emotions, break away from the idea of choosing a career for life and so on, and constantly strengthen their psychological quality. At the same time, college students must learn to self motivate, not be pessimistic because they are in temporary difficulties. Instead, student must encourage themselves and inspire them, build confidence and keep going on the road of career choice, and believe that they will always find jobs that can fulfill their talents. Finally, we should respond positively to the policy call of the state, go to the West, go to the countryside, take an active part in the grass-roots level, strengthen exercise, improve capacity and reward the society.

2) Striving to enhance their integrated capacities: First of all, college students should make reasonable plans for their career. College is the golden stage of career planning, which has a profound influence on the future career and career development of college students. The training of career planning is helpful to improve the comprehensive quality of college students and avoid blindness and passivity. Career planning plays an intrinsic role in motivating college students to learn and practice, and motivates them to work hard to achieve their goals and ultimate goals. Secondly, college students should seriously study and master professional knowledge, cultivate a solid professional foundation, continuously broaden their own knowledge, and learn to apply theory to practice, pay attention to the transformation of theory and practice, and strengthen their practical ability. Finally, we should improve the ability of social adaptation. College students should actively participate in collective activities, train team consciousness and exercise their own organizational management ability. Go to the grass-roots level, actively participate in social practice, and strive to improve their interpersonal skills.

\section{CONCLUSION}

College students are the precious wealth of human resources in the country and a high quality force in the modernization of our country. The state, universities and students should take the initiative and act together in order to alleviate the difficult employment situation of college students and enable them to contribute themselves to their employment and personal ideals while contributing to the modernization of the country.

\section{REFERENCES}

[1] Zheng Zhilai. Paradox and Structural Reforms of Higher Education [J]. Education Science College Students' employment, 2016,32 (04): 56-63.

[2] Zhu Ling. The Causes and Countermeasures of College Students Difficult Employment in China [J]. Continuing Education Research, 2016 (08): 80-82

[3] Zhao Haiyang. The Difficult Employment of College Students "Three Causes" Analysis and "Treatment Chosen According to Climate" [J]. China Adult Education, 2015 (08): 24-26.

[4] Zhang Xiaolin. College Students' Difficulties in Employment and Their Solutions [J]. Education and Occupation, 2014 (32): 116-117.

[5] Yao Xianguo, Zhang Haifeng, Le Jun Jie. Study on Labor Economy [J].Hard Industrial Transformation and Employment of College Students, 2014,2 (05): 34-47.

[6] Ryan Sheng. Where is the Difficulty of College Students' Employment in [J]., 2013 (20): 52-54.

[7] Xu Jing. Analysis of the Institutional Factors and Countermeasures for the Difficult Employment of College Students in China: [J]. Chinese Youth Research, 2013 (09): 100-104.

[8] Lin Chunli. A New Oerspective on Solving the "Difficult employment" of College Students [J]. People's Forum, 2011 (29): 156-157. 